\title{
3 Passerine Station Laboratory Equipment
}

The basic laboratory equipment should allow ringing and collection of standard measurements in an effective way and with the smallest possible effort. To some extent, the working routines at the laboratory site decide the needs, and not all items are necessary at all sites. The laboratory stand and tools presented here were carefully elaborated from an ergonomic point of view and checked during 50 years of Operation Baltic.

\subsection{Bird Transport and Storage Devices}

The basic container for transportation of passerines to a laboratory is a linen bag closed with a soft string (Figure 3.1) that could be hung up on a special hanger at the chest of the ringer (Figure 3.2), on a binocular, which is a very convenient solution, if the person is not simultaneously the passing birds observer, or, in the worst case, on a forearm (Figure 3.3), but not carried in the hand. Generally, two kinds of bag strings could be used: without or with a lock. In the first case, the string could be slippery, of a synthetic fabric. In the second case, string must be not too smooth, synthetic, but a cotton one. Both of these constructions have their own pros and cons. Bags with locks protect us better from escaping birds and make the sporadic addition of new birds easier, but the strings can easily entangle with each other when not well-packed into

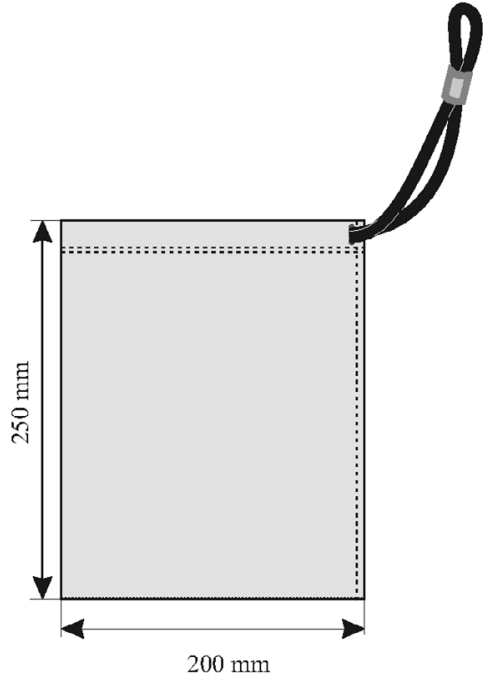

Figure 3.1 Bag for bird transportation.

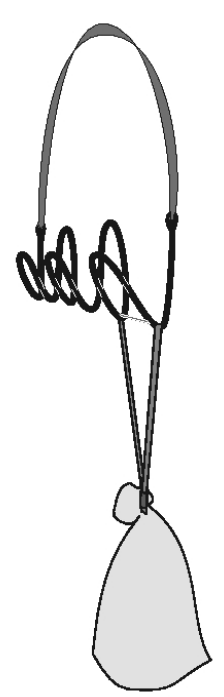

Figure 3.2 Breast hanger for bags. 


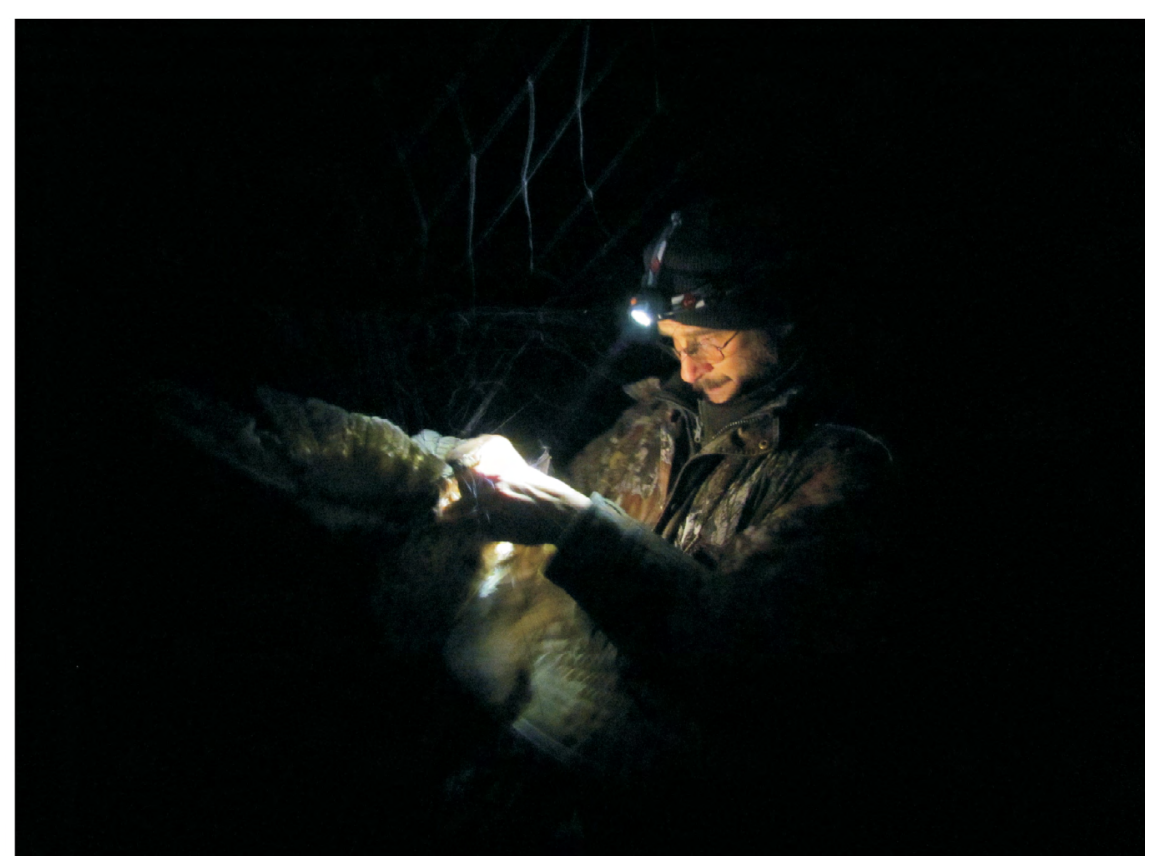

Figure 3.3-1: Extracting the owl during night net control. Kopań, Poland. Photo unknown.

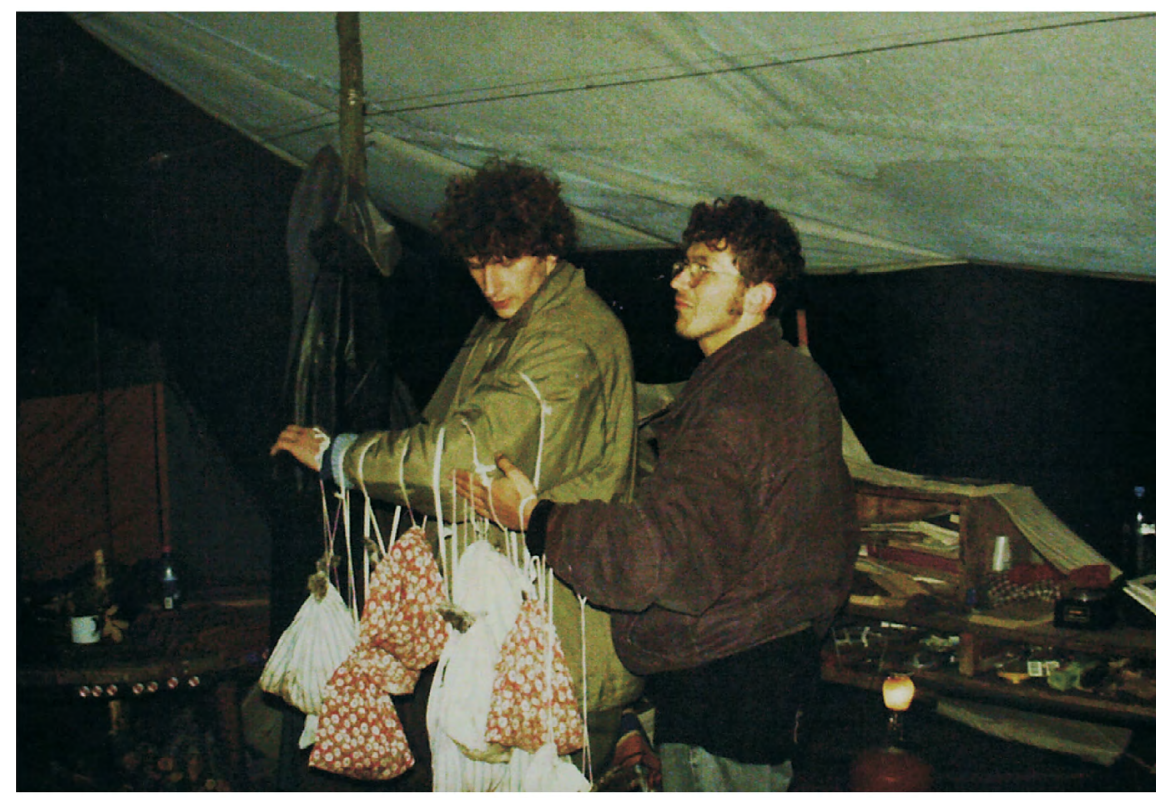

Figure 3.3-2: Good catch of owls. Because of weight of the owls caught bags are hanged on forearms. Kopań, Poland. Photo W. Busse. 
the pocket. The bags with strings without lock are more resistant to entangling, but if they are not closed properly, birds can escape. Additionally, if bags are closed, as many helpers do, the strings can get knotted, and these knots are not easy to remove, especially when wet. The size of the bags may differ - a small "one bird-person" bag may be used for transporting single individuals such as rare birds or birds with a foreign ring, while standard bags (approximately $20 \times 25 \mathrm{~cm}$ ) may be used for the majority of birds, but a different number of individuals according to size (Table 3.1), and special bags for bigger birds (e.g. owls, raptors, small waders). Standard bags should be numerous enough, at least 100 at the station where large number of birds is expected, since they are used to transport birds from the nets and temporarily store them while they are waiting for ringing and investigation (Figure 3.4). A deficit of free bags sometimes may cause dramatic disturbances in station work during peak days; birds will suffocate in overcrowded bags. Because of this, at the laboratory, the birds should be stored (when numerous) in special storing devices like boxes or baskets, where they have more space and do not risk suffocating when wet. One type of bags in use has hard plastic bottoms. Such bottoms should be with many holes, e.g. made of hard plastic netting, allowing excrements to drop out; in the worst case the birds will get dirty and wet, and the ringer is the cause of their impaired condition.

Table 3.1: Number of individuals allowed to be transported in one standard bag $(20 \times 25 \mathrm{~cm})$.

\begin{tabular}{ll}
\hline Species & Number of individuals* \\
\hline Goldcrest & $10-15-20$ \\
Long-tailed Tit & $8-10-15$ \\
Blue Tit, Coal Tit & $7-10-15$ \\
Great Tit, Robin & $6-8-12$ \\
thrushes & $1-1-2$ \\
Jay & $1-1-1$ \\
\hline
\end{tabular}

* First number indicates when birds are wet or they must wait longer time; Central number indicates standard number of individuals; Last number indicates number of individuals when they will be immediately put into storing devices.

The most important thing when preparing bags is to use linen that allows for the passage of air. Cotton bags usually have been washed before first use for removal of chemical apertures. A disadvantage of cotton bags is that they easily absorb water from excrement and moist birds. It takes long time for them to dry and they are more likely to be damaged by microorganisms when moist. Synthetic linens are much more excrement resistant, but they must have visible holes between threads, to be air transparent enough. Wet birds stored in synthetic bags are still wet when you remove them. On the other hand, wet bags could be easily dried. Bags should be regularly washed and in the meantime cleaned from droppings and feathers. 


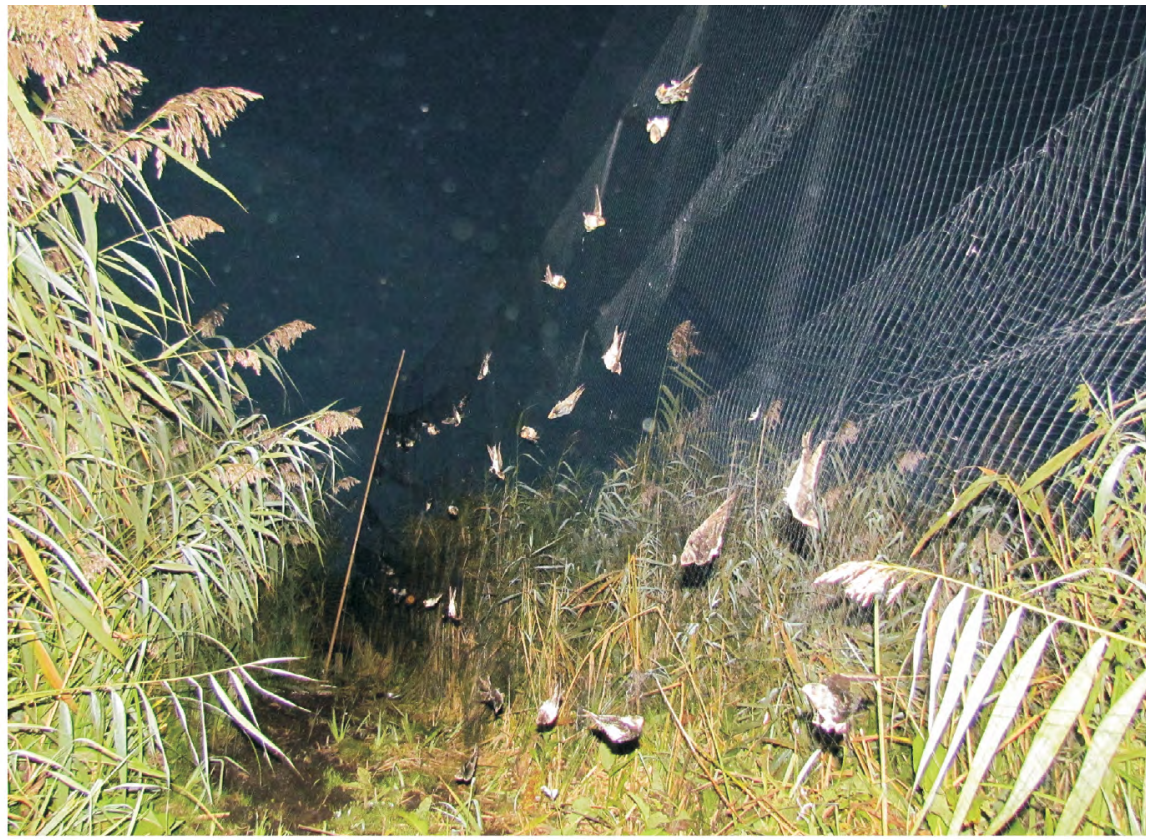

Figure 3.4-1: Good catch of roosting birds. Kopań, Poland. Photo W. Busse.

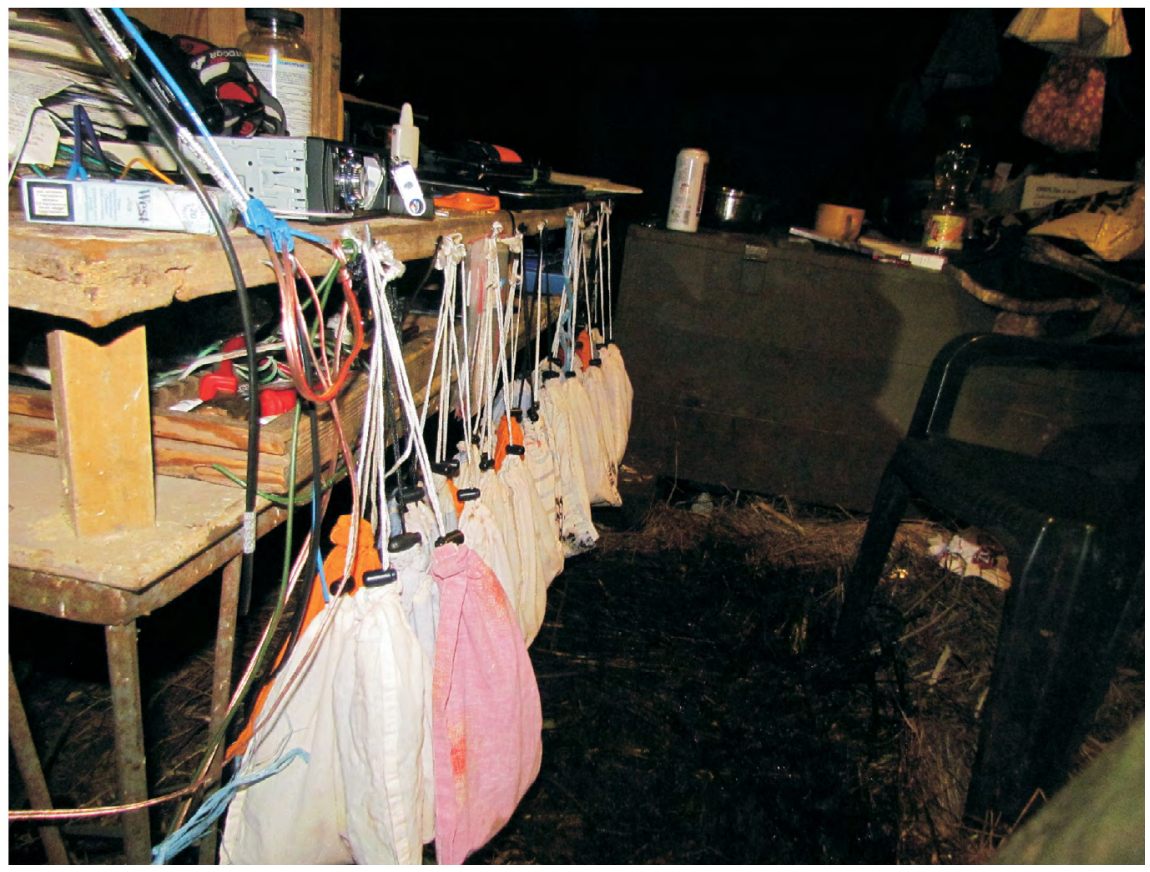

Figure 3.4-2: Bags with the birds caught at the roosting place. Kopań, Poland. Photo W. Busse. 
It is not advisable to use storing boxes or baskets (see below) to transport birds from the nets. There are only few exceptions when this is acceptable, e.g. when mass catches of one species occurs in a limited number of nets situated close to each other. In such a case one particular person, besides the person making regular checks, should use them, but birds should be placed in a bag first and then shifted into the box. The birds caught in Heligoland traps may be transported in the final trapping boxes if such are included in the construction of the trap.

During peak days, when a few species tend to be very numerous, it is convenient, sometimes even necessary, to use bird-storing devices where birds could wait for ringing. Such devices can be made from different boxes, baskets etc. (Figures 3.5 and 3.6-2). The most important points of construction are:

1. Free access of air - at least part of the walls must be made from small mesh netting. The meshes must be smaller than any bird head (heads must not go through!);

2. Easy handling of birds: they should be easily put into and in particular easily removed from boxes at the ringing stand (boxes are used when you are in a hurry!),

3. Easy to move - storing devices should be kept in a cool, dark place and then moved to the ringing stand. But note: movable does not mean "used at the nets"; this is acceptable only under special conditions (see above).

The holding capacity of any particular size of box or bag depends on the particular species that is going to be stored in it, this must be estimated from case to case. Each bird should be able to sit on the floor; in most species the limit is set by that area of the bottom. Some species, however, will cling to the bag walls or to the ceiling of a box (e.g. goldcrests, tits), and the number may be increased accordingly. But watch out for indoor temperature increases when there is much stress among the birds; a bag full of "over-heated" goldcrests or siskins will kill itself in no time, and the losses of humidity may be harmful to birds.

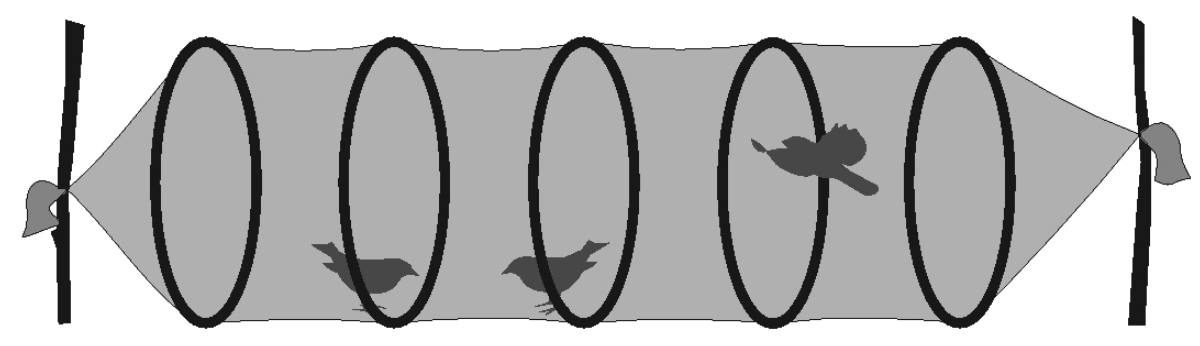

Figure 3.5: Example of how Passerine birds are stored. 


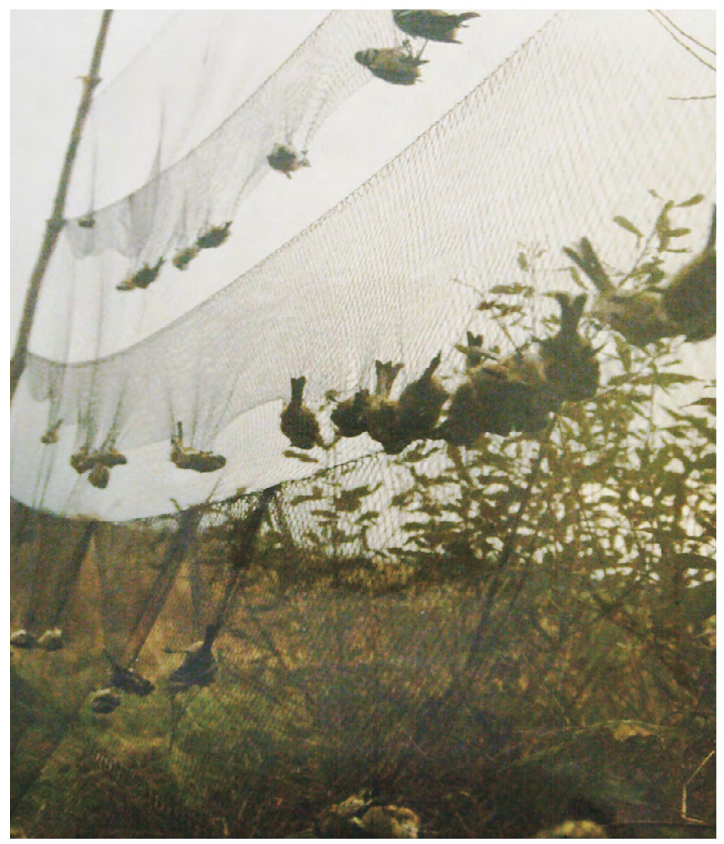

Figure 3.6-1: Good catch of tits in the net. Kopań, Poland. Photo W. Busse.

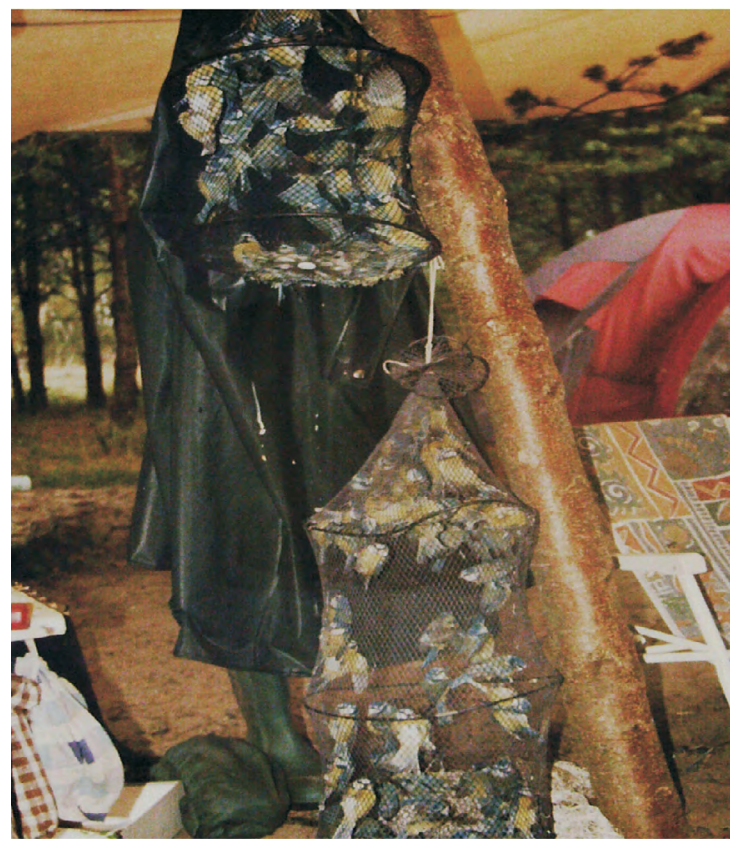

Figure 3.6-2: Many tits waiting for ringing. Kopań, Poland. Photo W. Busse. 
It is better to have few smaller boxes than a few big ones. In one box, birds from only one check, and obviously of one species, can be stored.

In exceptional cases, boxes may be used for overnight storage of diurnal migrants ringed late in the evening when the weather is bad (rain, fog, snowfall) or the owls migration is ongoing. In such cases, the number of birds per box should be reduced by more than 50 percent of the standard. Night migrants should be released during the night unless many owls hunt around. At roosts, swallows and wagtails may be let free in total darkness when they are no longer blinded; they settle in the reeds without delay. If bigger number of birds are ringed and released in darkness, an additional check of nets close to the ringing site should be performed.

\subsection{Laboratory Tools}

The ringing laboratory tools are shown in Figure 3.7.

Ruler. Depending on method of measurement, different types of rulers are used (Figure 3.7 (1-3)). The most common one is a metal ruler with a stop at zero-end. It is used for a maximum chord measurement of the wing, while tail measurements are not possible with this type because of the stop. Wing-formulas may be measured with this ruler as well, but the procedure is less convenient. Stop rulers must be carefully checked for precision. In some cases, the stop is not properly fixed. Special rulers with a pin (1.4 $\mathrm{mm}$ in diameter) fixed perpendicularly to the ruler at zero line is used for 3rd primary measurement. The most universal tool is, however, a ruler without the stop and cut off exactly at the zero-end. The length of this ruler is $30 \mathrm{~cm}$, and it can be used for wing-formula, wing-length and tail-length measurements. Winglength measurements taken with this type of ruler are exactly comparable with measurements taken with the stop ruler and a common opinion about their lower accuracy is unsound.

Balance. Very convenient, and not too expensive, are electronic balances with digital reading and a battery power supply ((Figure 3.7 (5)). Loads up to $500 \mathrm{~g}$ and exactness $0.1 \mathrm{~g}$ are ideal for most of netted passerine birds. There are balances of even more than $500 \mathrm{~g}$ capacity and $0.1 \mathrm{~g}$ exactitude. The balance of bigger capacity and lower exactness could be useful when waders or raptors are caught more frequently. The birds are weighed being put on the balance inside of a conic plastic tube adjusted to the size of the bird; there will be a resulting pull of $1-5 \mathrm{~g}$ when the weighing in a bag and the bird flutters from side to side. The balance should be protected against wind that can greatly disturb reading. The most common type of balances used in the field by amateur ringers is spring balances of Pesola type (Figure 3.7 (4)). They are intended for different sizes of birds and measure with different degrees of precision. A full-scale load of $30 \mathrm{~g}$ and exactitude $0.1 \mathrm{~g}$ is applicable for most small passerines. 

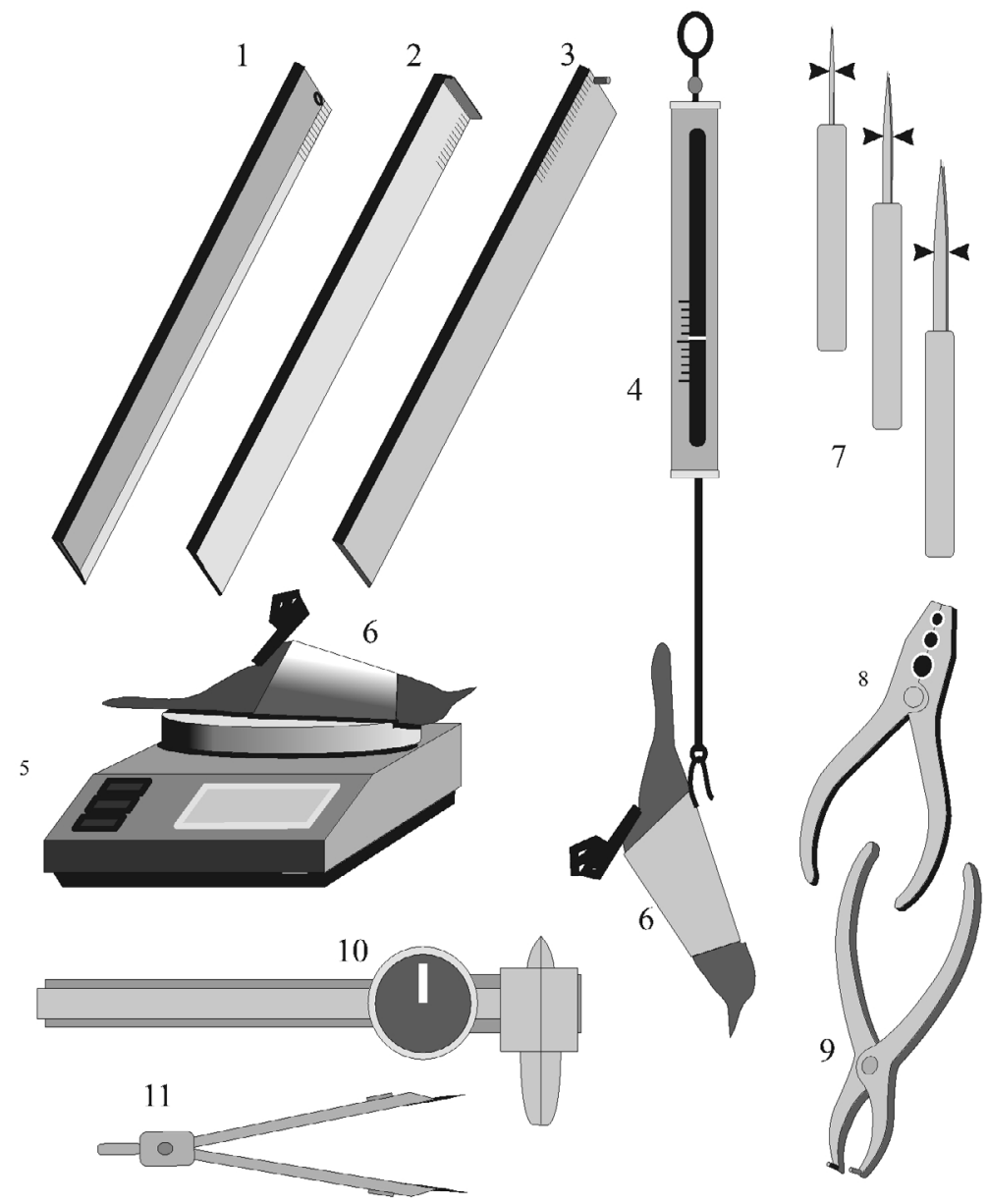

Figure 3.7: Laboratory tools. 1. Ruler without a stop, 2. Ruler with a stop, 3. Ruler with a pin, 4. Pesola balance, 5. Electronic balance, 6 . Tube for weighing the birds, 7. Openers for opening rings (note that from arrows to the hand side surfaces must be parallel), 8. Pincers for closing rings, 9. Reverse pincers for opening rings, 10. Callipers, 11. Dividers.

Balances of bigger capacity (full scale 100 g, 300 g, 1000 g) and lower exactitude come into use where heavier species are involved. For small birds, their exactitude is inadequate. The birds weighed are hanged to the balance in a conic plastic tube (Figures 3.7 (6) and 3.8) adjusted to the size of the bird (weighing the birds in bags is not recommended). For the modern station work Pesola balances could not be recommended because of two properties: it is much more time consuming, especially if one has a bad habit of weighing birds in bags, and it loses precision with time. The spring elongates during normal use and also extends at high temperatures while shrinking at cold temperatures, so it should be calibrated at both ends of a scale. 


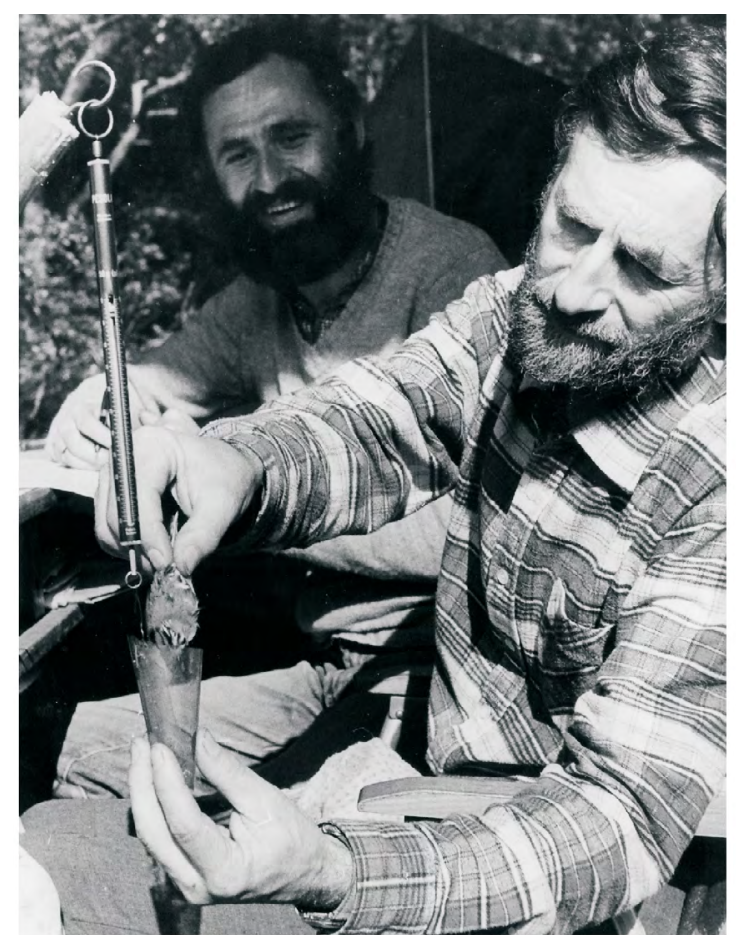

Figure 3.8: Weighting of the bird using Pesola balance in the last century. Mierzeja Wiślana, Poland. Photo Unknown.

\subsubsection{The Orientation Tests Equipment}

The described method of studying directional preferences in nocturnal migrants includes a new field technique that pays special attention to the inconsistency of directional behaviour pattern in an individual bird. It may be used under real field circumstances, by professionals as well as amateurs. The equipment is simple and cheap, and the technique easy to learn in a standardized form. Additionally, the test routine allows for a great deal of data collection, since tests may be performed during both night and day. Diurnal tests under an overcast sky have the same value as tests done with good sky visibility, which is not the case in nocturnal tests. Analysis of local vectors in a directional behaviour pattern seems to be of use in the studies on local migratory directions and the overall population composition of migrants. The method used commonly by researchers (Emlen's cage) is much more stressing the birds, needs much more effort (time and material). The equipment set includes:

1. Circular, not transparent, uniformly coloured screen, which keeps the bird in an experimental cage from seeing any landmarks, trees, wires etc. (Figure 3.9). Its diameter is $110 \mathrm{~cm}$ and its height $40 \mathrm{~cm}$ and it is made of four sectors for easier transportation (Figure 3.10-1). 


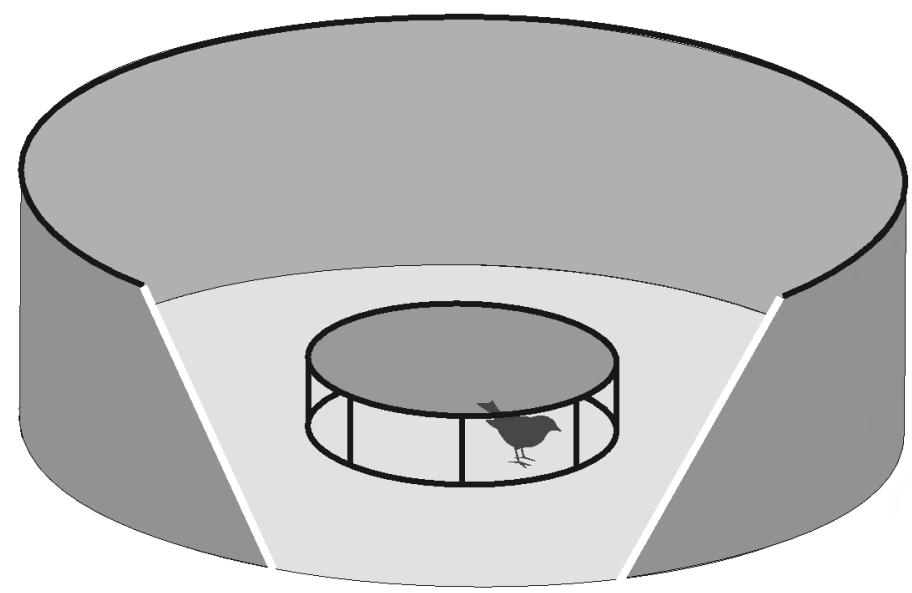

Figure 3.9: Orientation tests set: protecting wall around and experimental cage inside.

2. Testing cage (Figure 3.10-2): a cylinder cage made of two wire circles connected by eight vertical wires distributed evenly. These define sectors used when counting results. Diameter of the cage: $36 \mathrm{~cm}$, height: 10 or $12 \mathrm{~cm}$. Higher cages are used for testing thrushes, but they may be used for smaller birds as well (since differences between results obtained with these two heights were not found). The top surface of the cage is covered with nylon netting of $10 \mathrm{~mm}$ mesh. The sidewall is covered by a strip of ultra-thin, transparent plastic foil used to keep food in refrigerators (sold in rolls).

3. Not too slippery plate of neutral colour as a bottom surface under the cage or piece of linen to cover smooth ground.

4. Forms for recording the collected data.

5. Pointed colour marker.

Some useful details of the orientation stand equipment are in the description of the method (Special Studies, p. 102).

Other tools. Bird rings may be opened with particularly designed openers (Figure 3.7 (7)); if there are not many to do, a sharp knife or hard nail will suffice.

In many ringing schemes, pincers with side holes are used for closing all rings. This gives a very exact closure of the ring, without fissure that might be harmful to the bird. In some countries, small aluminium rings are simply closed with the fingers, while larger rings (with locks) and rings made of stainless steel are closed with pincers (Figure 3.7 (8)). The "finger closing" technique needs very high quality rings, preferably not much opened and not too hard. Closing small rings with the fingers will speed up the ringing procedure, but the ringer must be well trained and take care 


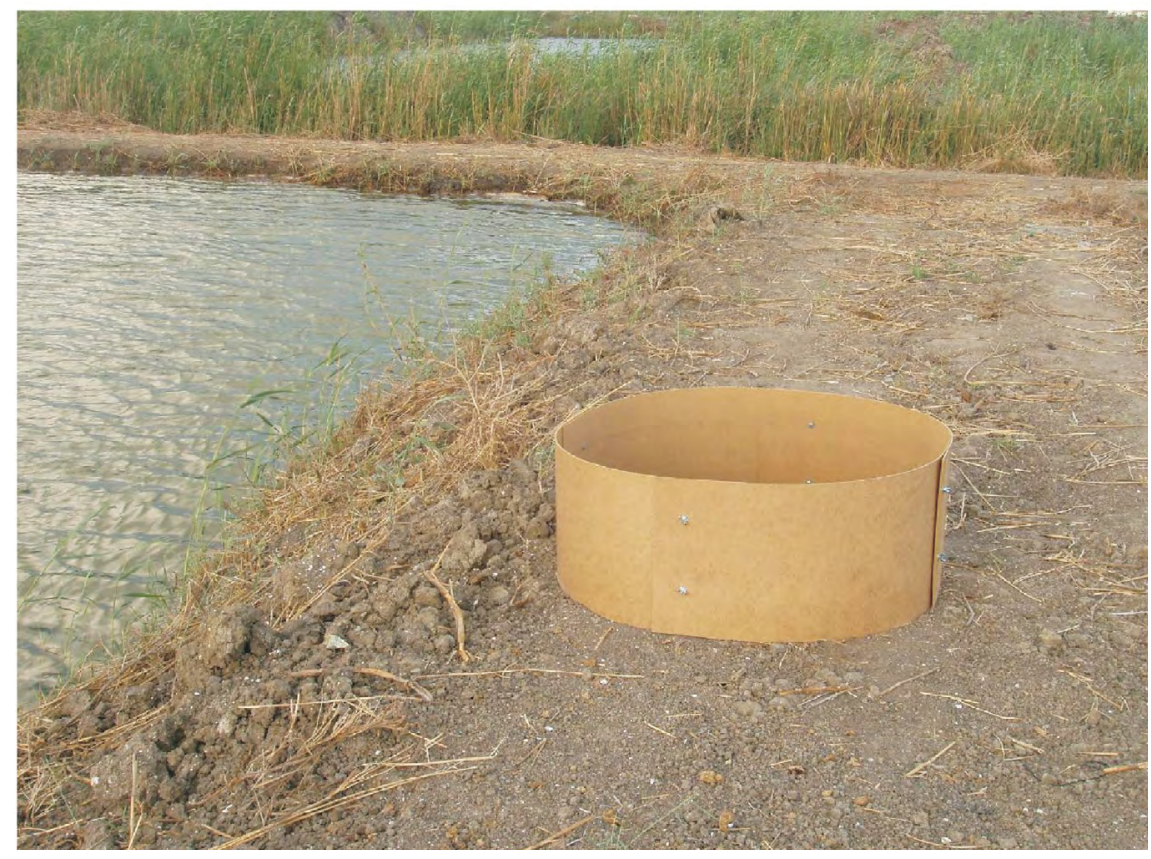

Figure 3.10-1: The orientation tests stand in a field. Burullus, Egypt. Photo P. Busse.

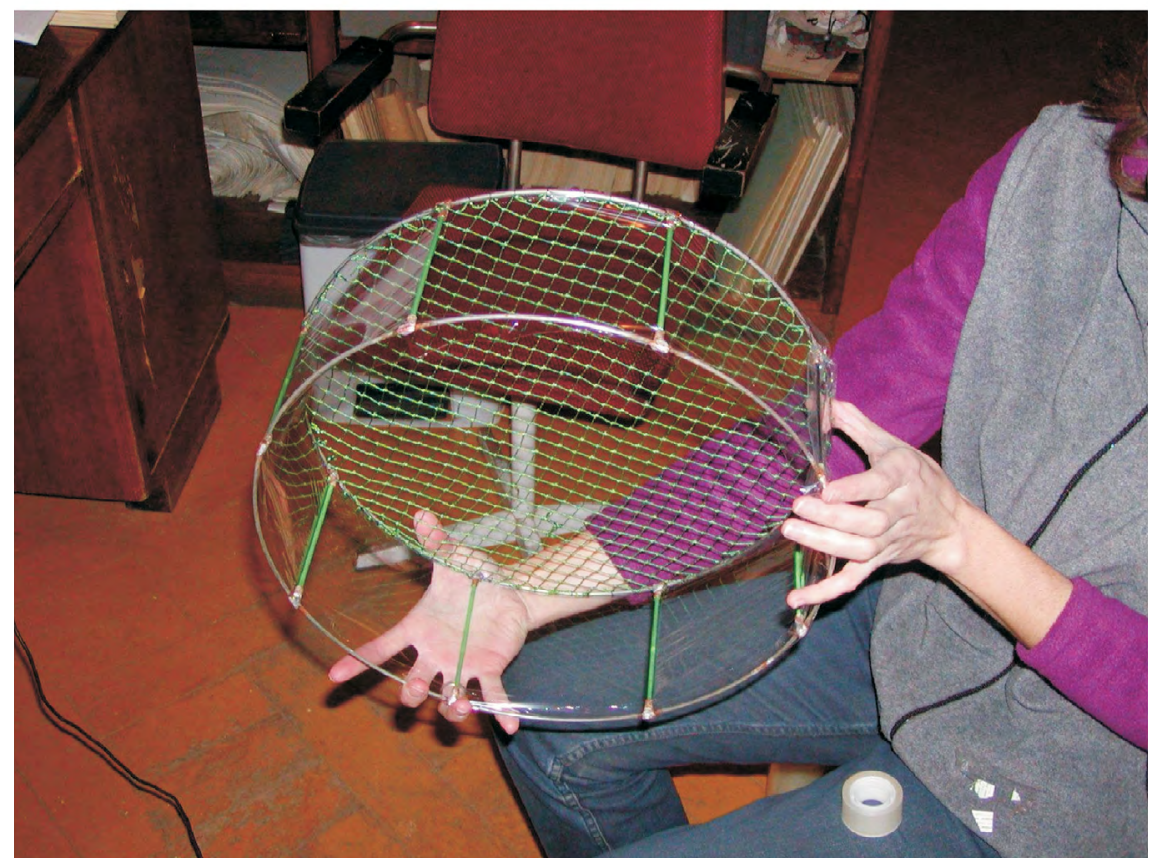

Figure 3.10-2: Demonstration of internal orientation cage. Photo P. Busse. 
to close the rings properly. However, after a day's hard ringing work, the fingers will be very sore and could be less accurate!

Special technical reverse pincers (Figure 3.7 (9)) may be used when a closed ring has to be removed from a bird's leg, but note that operations of this kind can be performed only exceptionally, when the ring is dangerous to the bird. In most cases, removal of a ring is very difficult and the whole procedure may injure the bird leg. When a stainless ring is bent over it may be better not to mess up things more than they already are. However, one ringer had the idea, apparently effective, to use two loops made of strong, but thin stainless steel wire loops with little hands as shown on Figure 3.11.

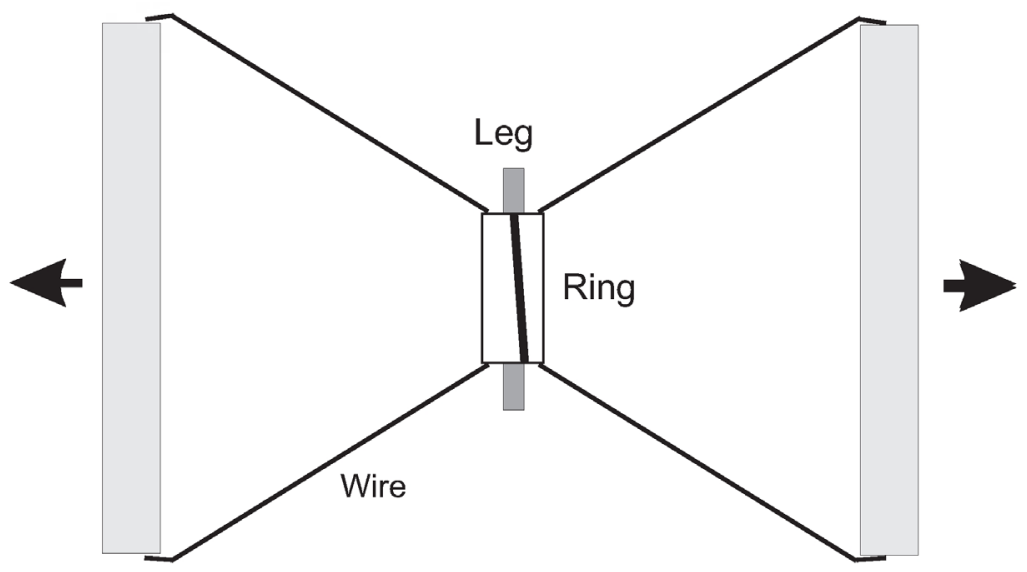

Figure 3.11: Opening of the stainless steel ring.

Colour rings need special applicators to put them onto the bird's leg. There are different applicators depending on the type of plastic rings. Colour plastic rings must be glued when closing.

Callipers (Figure 3.7 (10)) are used for tarsus and bill measurements. They must be of good quality and slip easily - the bird tarsus is not made of iron! The best, but also most expensive, are modern types with digital reading. Less expensive ones are plastic callipers with round, clock-like scale. The cheapest, but definitely the worst quality, are the traditional ones; however, measurement is much more time consuming.

Dividers (Figure 3.7 (11)) are used for tarsus, bill and sometimes tail-length measurements. Measurements taken in this way are less precise and more time consuming. Recently, dividers have gone out of use. 


\subsection{Rings}

The rings must be open and easily removable from sticks or strings. They are supplied in an opened state and either threaded on a plastic string or stored in a tube. However, to remove them from the string could be difficult during ringing work; all rings will not easily slip from the elastic string. So, best way to prepare in advance is to shift them from the string to a metal wire stick of a slightly smaller diameter (Figure 3.12). Rings must be open enough to be put on a tarsus of the largest birds ringed with the particular ring size. If they are too closed, the ringer should open them to proper fissure size in advance and put them on adequate sticks. The rings must be opened only with a proper opener. Rings opened in a wrong way (Figure 3.13) cannot be properly closed and could be harmful to the birds. The bottom side of the ring number must be down the stick. Rings of rarely used sizes may be kept unopened and stored on the original strings. After ringing, its position on the bird leg is most convenient when ring number is read during retrap handling; this greatly reduces number of reading errors. Most small passerines are checked as re-traps in the hand, not by sightings (as for bigger birds), so this style of positioning rings prevents misreading the number, especially in hurry, the ring number is better protected against wear when it is located at the bottom of the ring. However, rings put on waders and birds should be oriented in such a way that the number could be easily read from a distance.

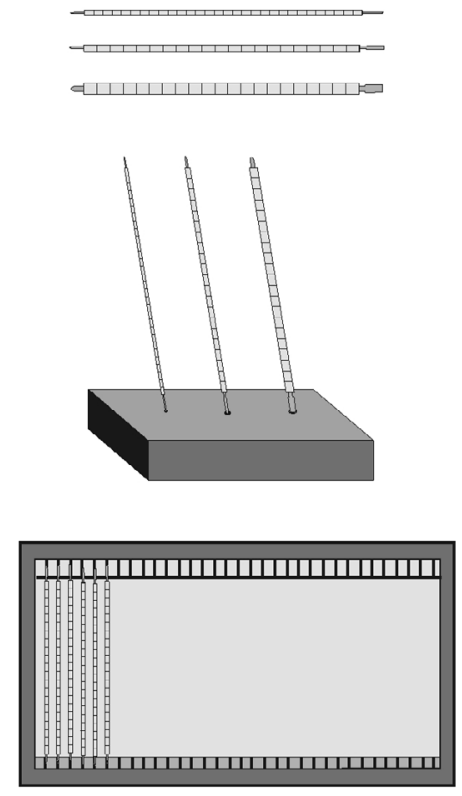

Figure 3.12: Handling of open rings: the sticks for different sizes of rings, working position and a box for storing the sticks. 

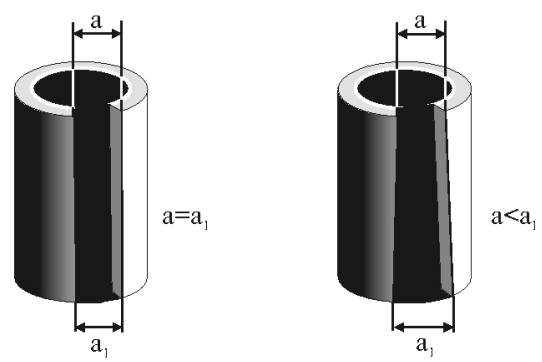

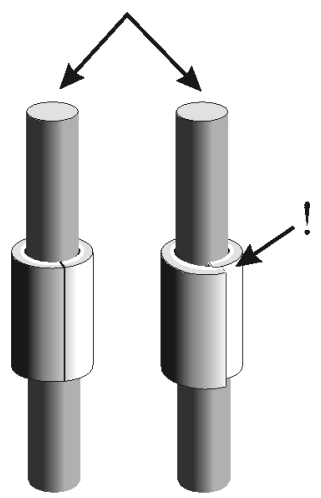

WRONGLY

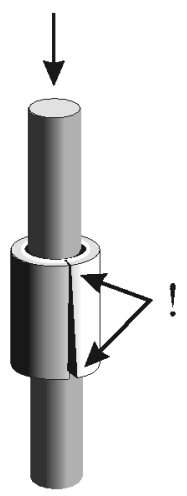

WRONGLY

Figure 3.13: Correctly (upper left) and incorrectly opened ring (upper right); correctly (lower left) and incorrectly closed rings (right). Note that incorrectly closed rings are harmful to the bird!

Colour rings are more often used in ringing programmes run during migration (Meissner \& Bzoma, 2011). They are also useful in ecological studies during the breeding season. In recent years, the number of different colour ringing schemes has increased (see www.cr-biding.org). The main benefit of using colour rings over standard metal rings is the possibility of obtaining a recovery without catching the bird. Colour rings increase recovery rates, especially in the case of larger birds, when the inscription on the ring is big enough to be read easily from a distance. In projects involving individual marking of hundreds or thousands of birds, it is advisable to use plastic rings engraved with a unique field-readable code. 


\subsection{Ringing Stand}

The ringing stands may be different from that described here according to logistics and expected number of the birds caught, but ultimately, they should be comfortable for people and birds.

The ringing stand (Figure 3.14) should be fitted with two or three comfortable seats, and a table that allows convenient writing in notebooks (see Laboratory Working Routine - p. 118); you may have to spend many hours without a break there. A couple of rows of hooks for bags with birds should be fixed to the edge of the table, the distance between each hook should be so large that the bags do not press against each other. Every row of hooks is intended for birds removed during one control walk. It is advisable to have at least 4-5 rows, as there may sometimes be a need for more than one row. One of the rows should be within hand range of the ringer. In front of the ringer, a row of sticks with rings of sizes most commonly used should be placed. The rings MUST be open and easily removable from the stick or string. Consecutive sticks or strings of rings should be easily accessible to the ringer and stored in top order to prevent one of them from being left out when the next sequence is needed. A set of ringing tools should always be placed within hand range: ruler, pincers (used at least for larger rings and rings of stainless steel), callipers or dividers (if used for special measurements) and scissors (accidentally used). The balance should be conveniently located according to the type used and the organization of work (as to who reads the weight: see Laboratory Working Routine - p. 118). If the ringing stand is organized in a room or closed tent, a convenient releasing funnel is needed. Passing the bird to another person to release it outside of the room is extremely inconvenient, and frequently birds escape into the room if workers are not trained well in passing birds (see later in Normal Routine - p. 119). For evening and night ringing, a good source of light must be arranged. The best are halogen $12 \mathrm{~V}$ lamps, while lighting diode head-torches could be useful too; note, however, that this kind of light changes our perception of some colours, thus, e.g. fat scoring is much more difficult as well as discrimination of some species or age and sex groups by colouration.

When the weather is warm enough and not too windy, the best solution is to have the ringing stand in the open (Figures 3.15 and 3.16), but under a tarpaulin roof protecting against rain and direct sun. Only very temporary ringing stands could be unsheltered (Figure 3.17, 3.18-1). In lower latitudes, a shade stand is absolutely necessary. One advantage with the open-air laboratory is that the bird can be let free without delay when it has been handled, and if it escapes, it can fly freely without hitting a window. In an unsheltered laboratory, however, the conditions will sometimes be too windy for accurate weighing, or a little on the cold and wet side for human beings - although nobody died as a consequence of that as far as reported. The material of the roof should be of neutral colour (white or grey) and preferably half-transparent since good light will facilitate sexing and ageing based on subtle colour characters. The same applies to the colour of walls inside a laboratory room. 

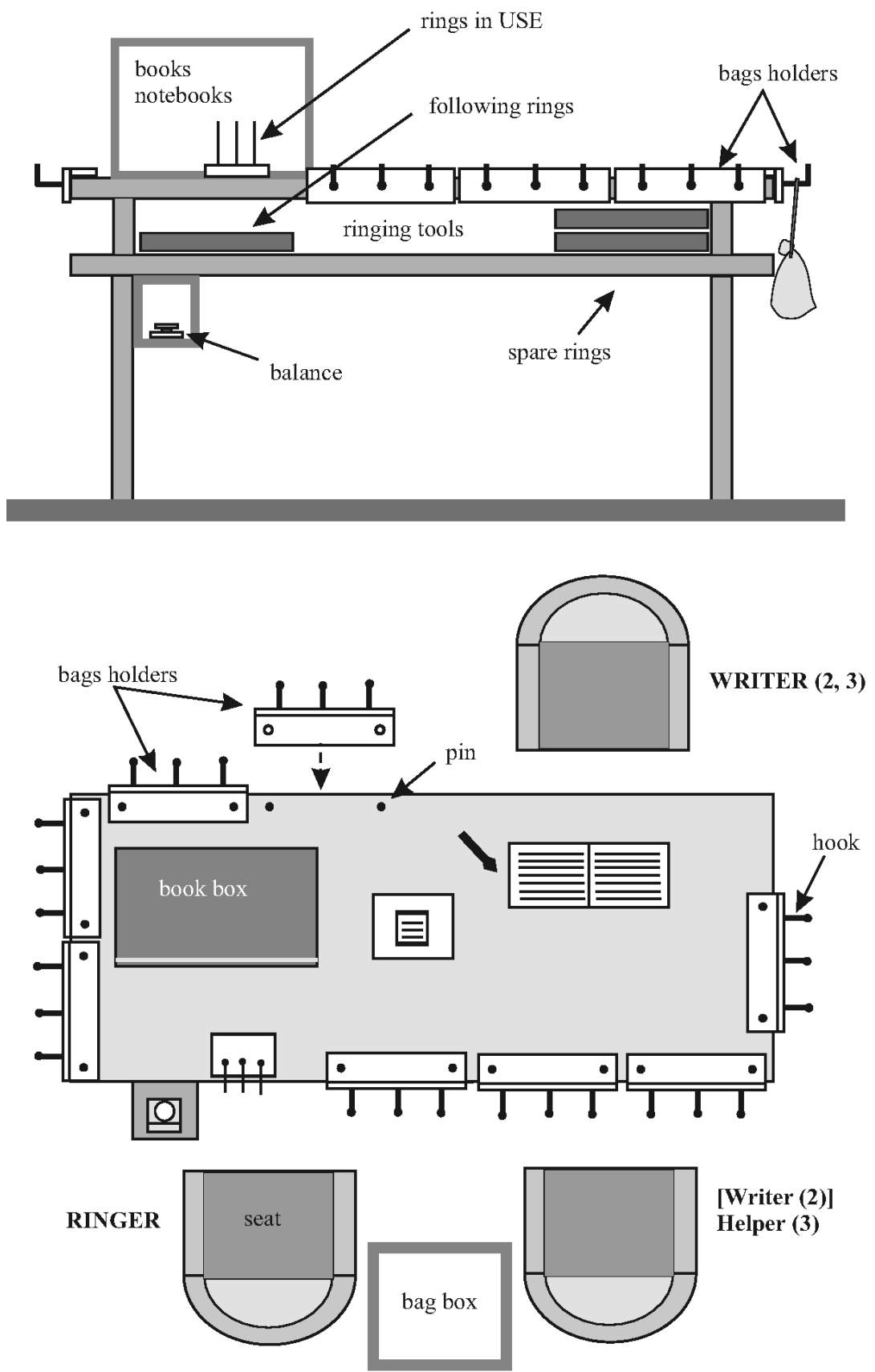

[Writer (2)]

Helper (3)

Figure 3.14: Fully equipped laboratory stand: explanations in the text. 


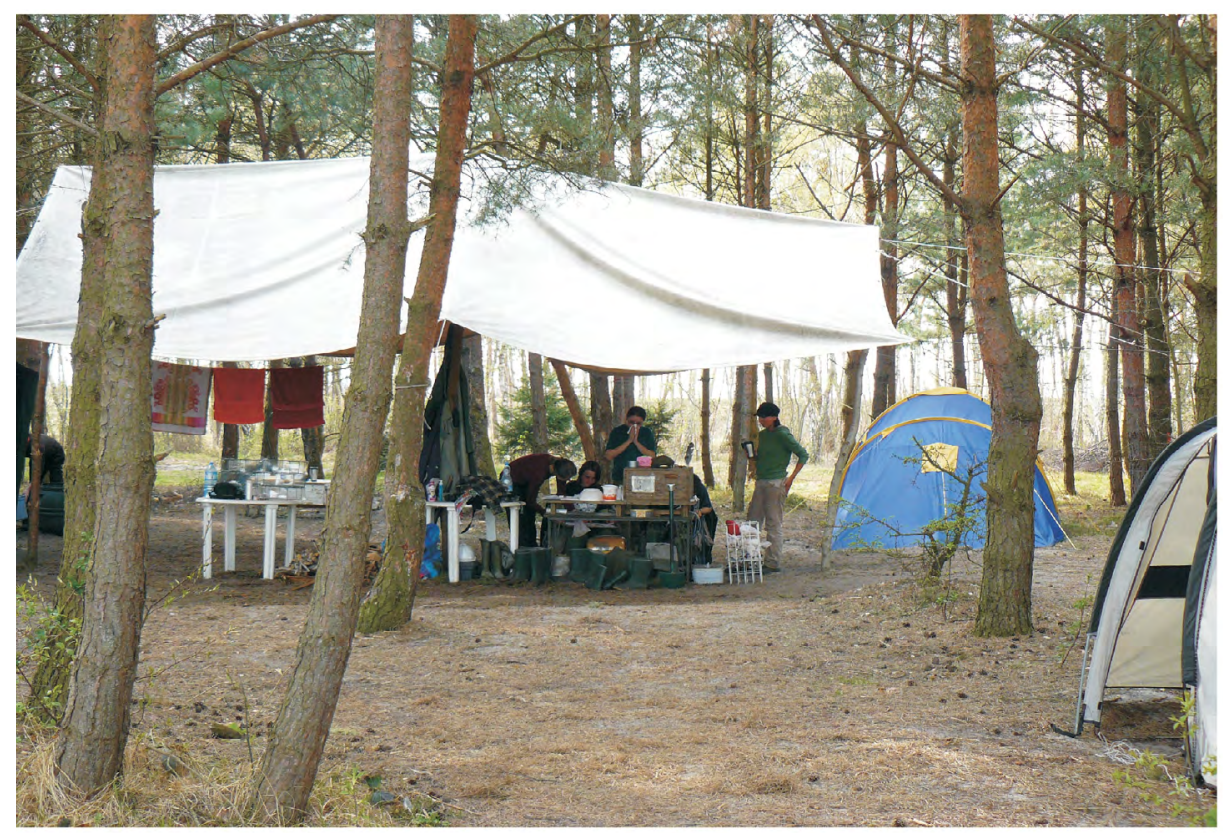

Figure 3.15-1: Seasonal bird ringing station - Kopań, Poland. Photo P. Busse.

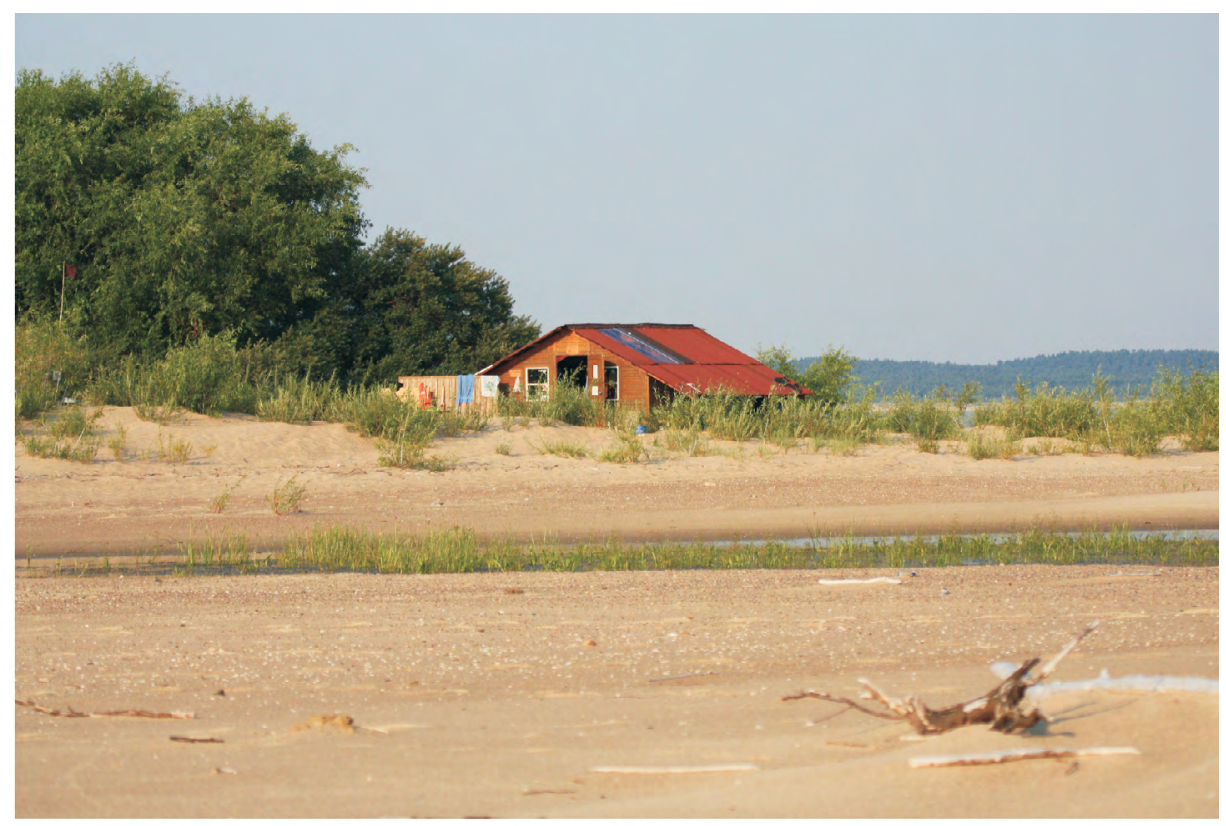

Figure 3.15-2: Seasonal bird ringing station - Mouth of Vistula, Poland. Photo W. Meissner. 


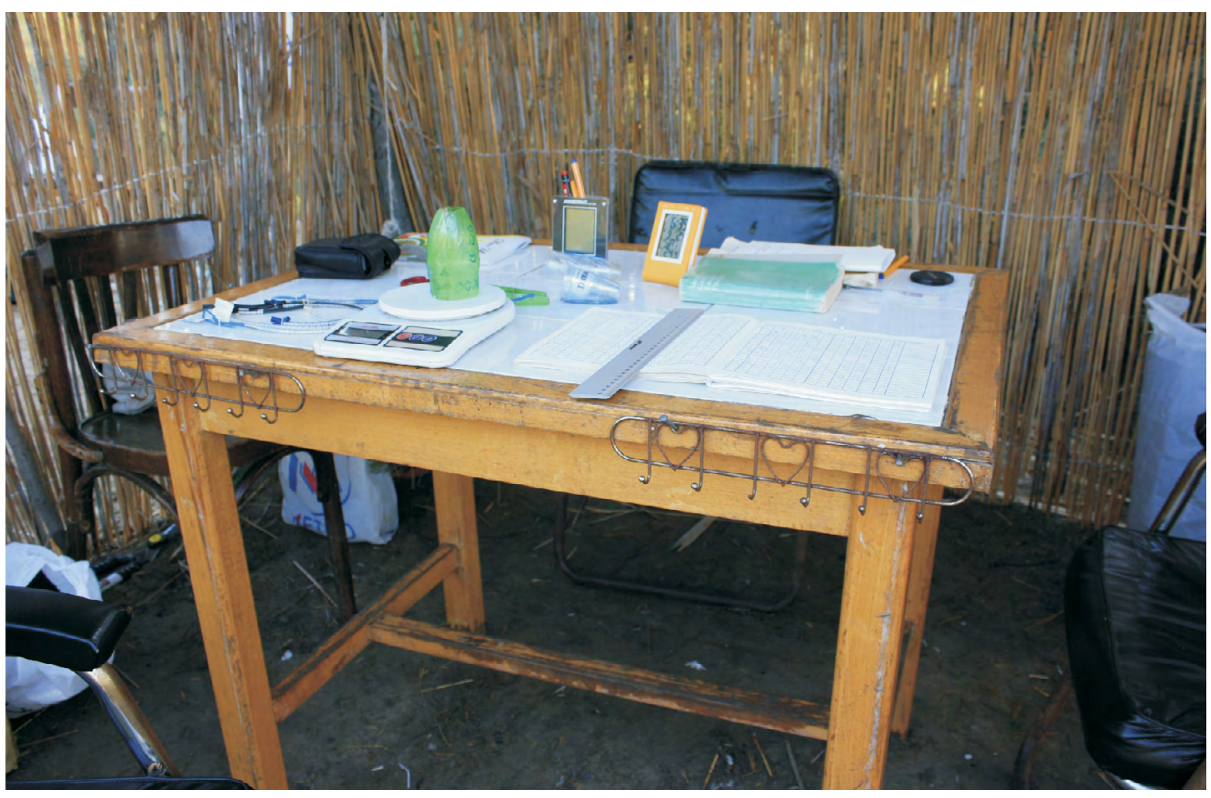

Figure 3.16-1: Seasonal bird ringing stand - Ashtoum, Egypt. Photo W. Kania.

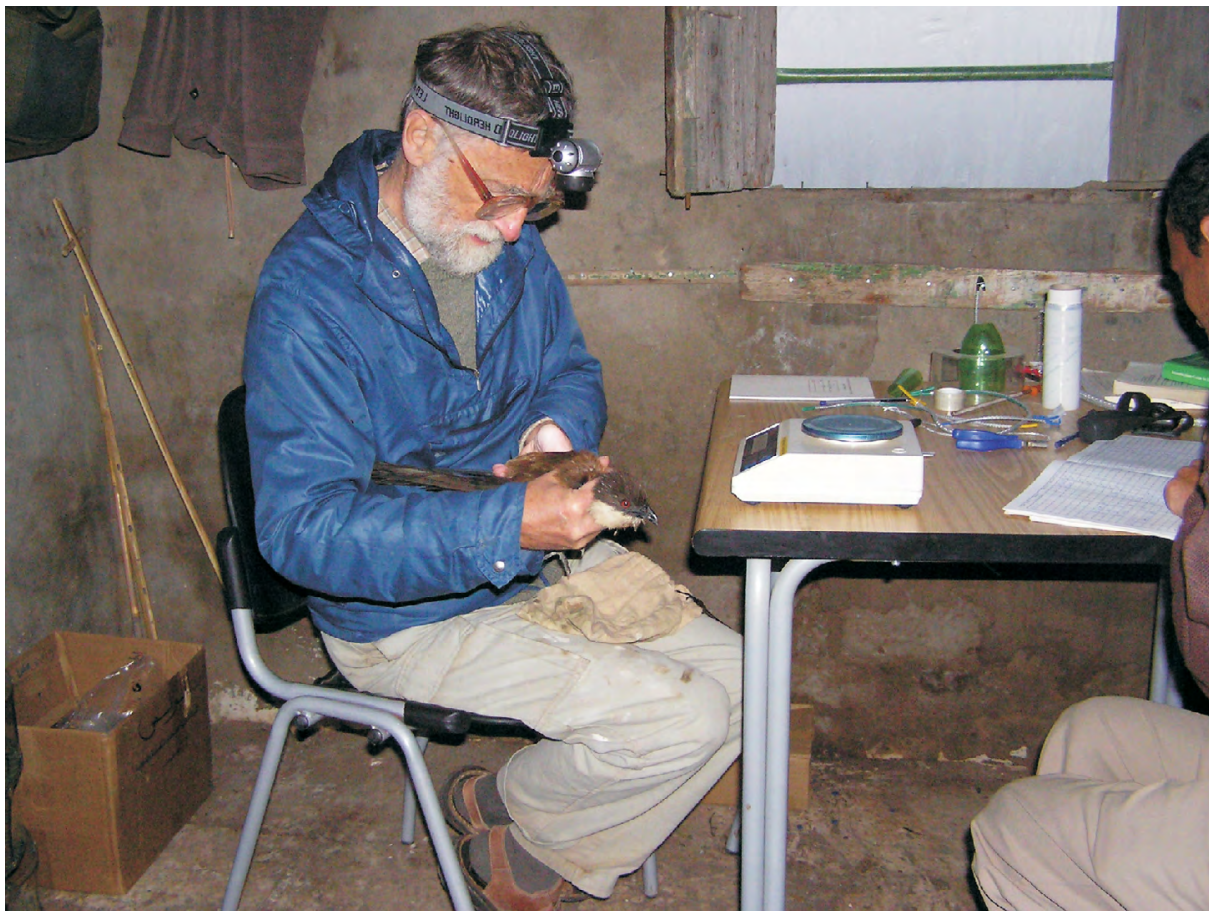

Figure 3.16-2: Seasonal bird ringing stand - Burullus, Egypt. Photo L. Maksalon. 


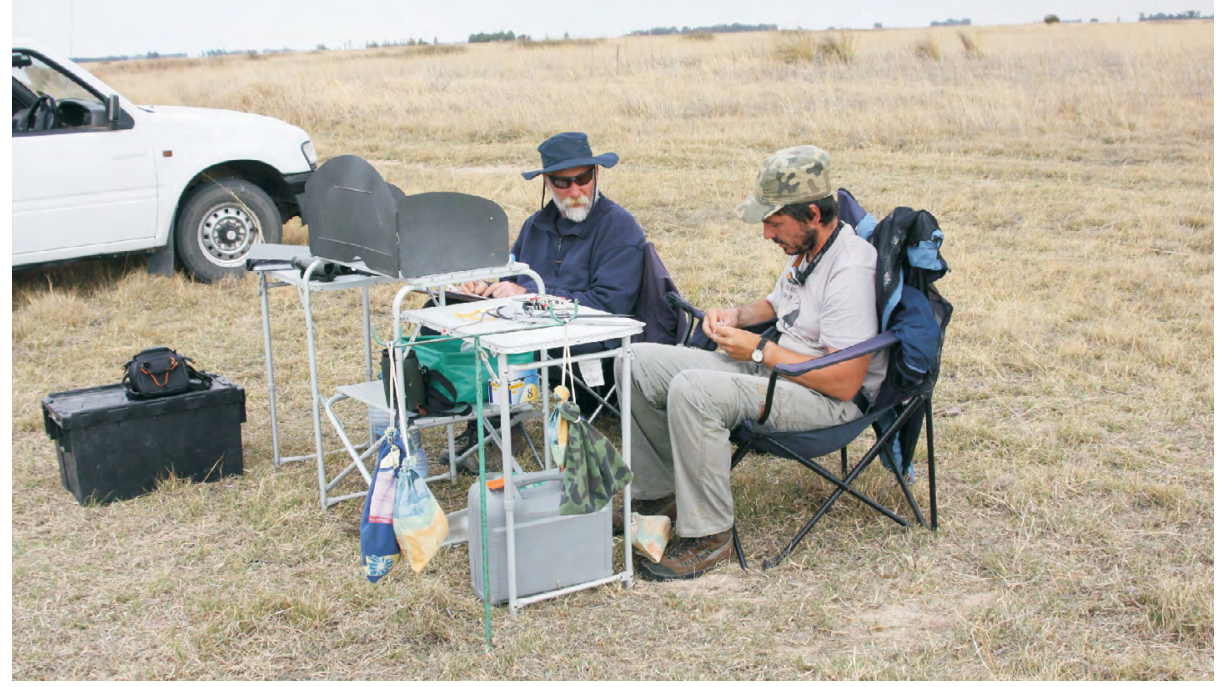

Figure 3.17-1: Provisory ringing stand - Barberspan, South Africa. Photo L. Pilacka.

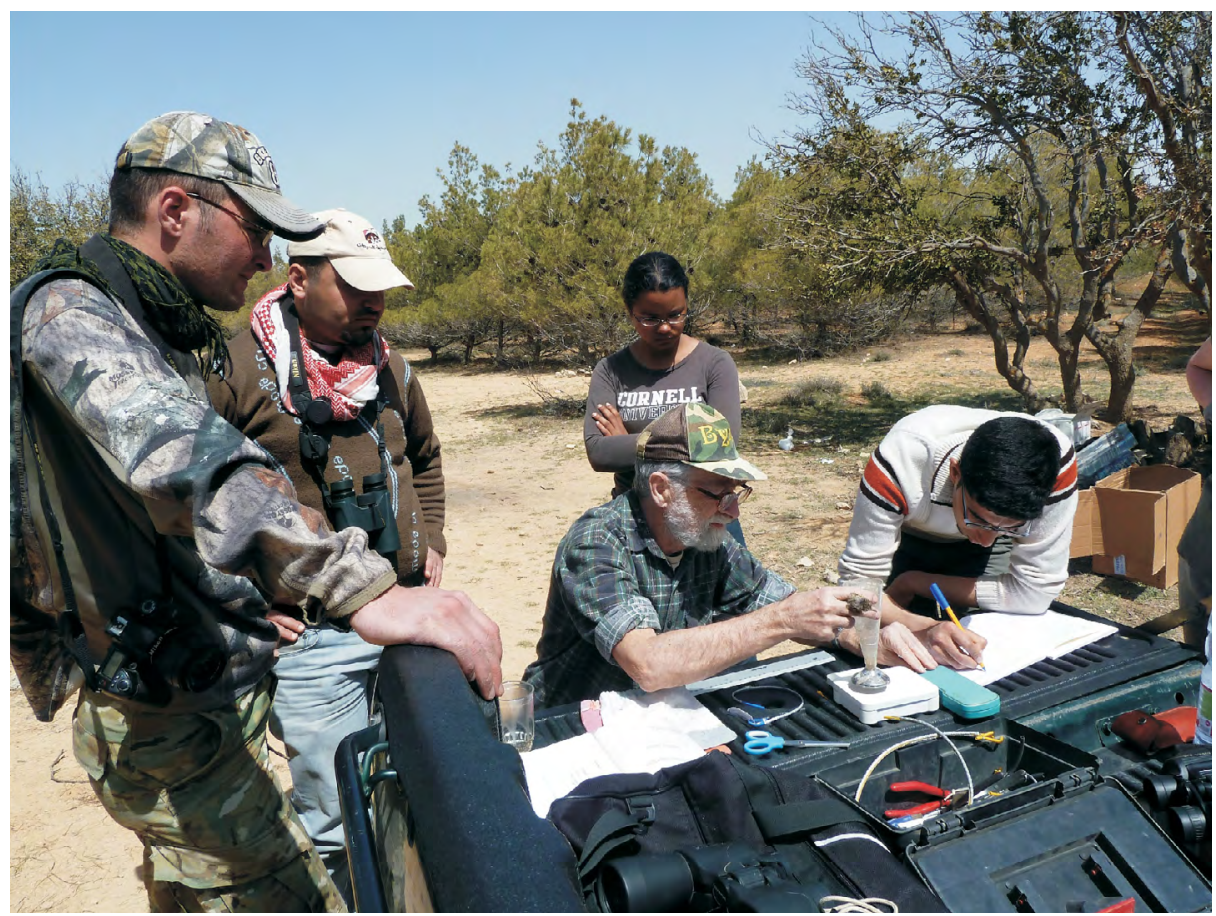

Figure 3.17-2: Provisory ringing stand. Wadi Dana spring, Jordan. Photo I. Rząd. 


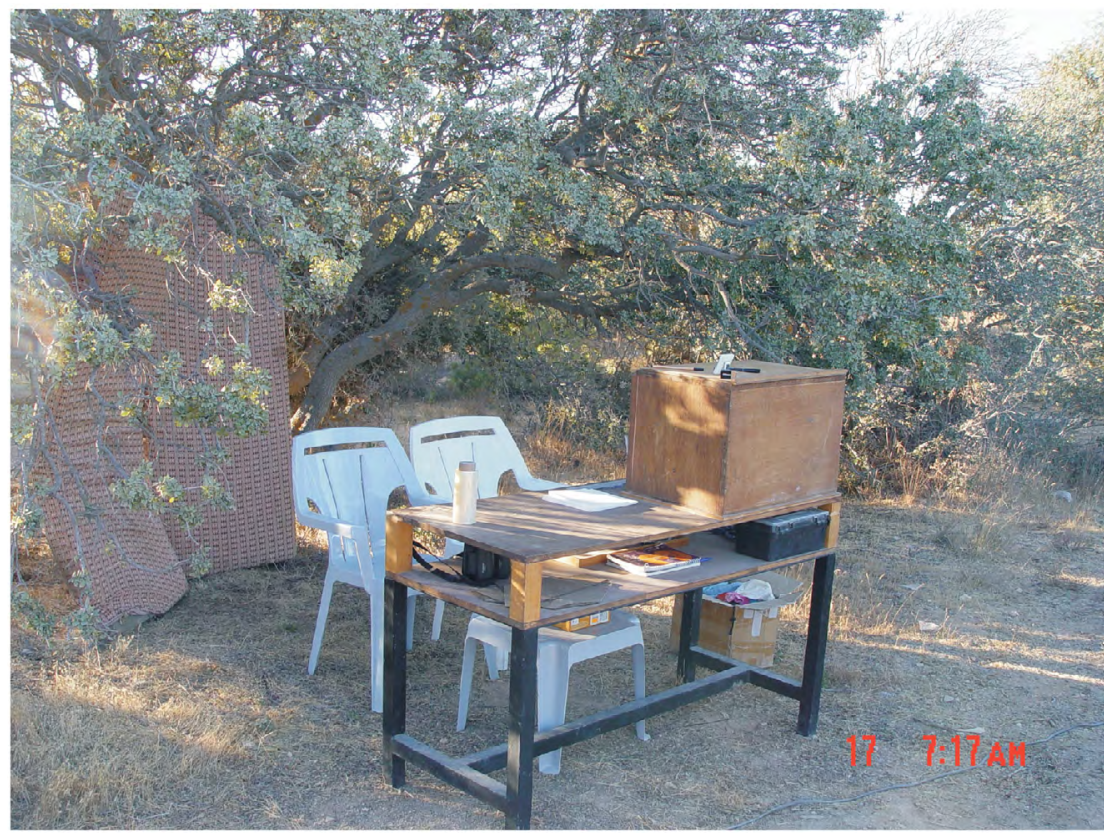

Figure 3.18-1: Temporary, but well equipped ringing stand in a dry area. Natural shadow. Wadi Dana autumn, Jordan. Photo P. Busse.

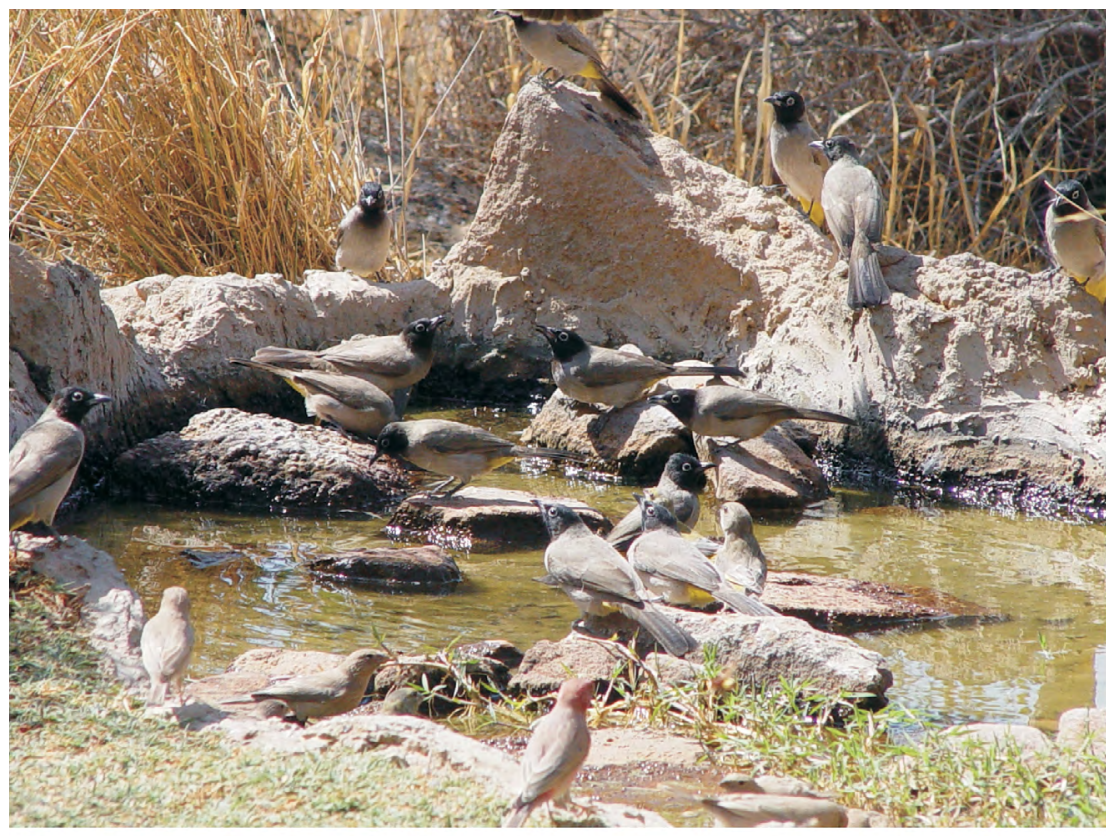

Figure 3.18-2: Natural pool attracting the birds. Jordan. Photo K. Alomari. 